\section{A case of resistant hypercalcemia in a peritoneal dialysis patient with underlying Vitamin A toxicosis}

\author{
Anas Diab*, Beth Pellegrino, Michelle M Neuman and Kareem Diab \\ Department of Medicine, Section of Nephrology, West Virginia University, Ruby Memorial Hospital, \\ Morgantown, WV, USA
}

\section{Introduction}

Hypercalcemia in End Stage Renal Disease on Dialysis, is a frustrating complication for both medical staff and patients, and it may lead to vascular calcification, Calciphylaxis, and even aggravating cardiovascular disease, even in the absence of risk factors which can lead to early death [1], and correcting Hypercalcemia even in the absence of hyperphosphatemia is out most important to improve co-morbid conditions and reduce mortality, most common causes in end stage renal disease, includes high calcium dialysis bath, high dietary intake of Calcium rich food, exogenous intake of calcium products, or excessive intake of Vitamin D, underlying Sarcoidosis, rare causes need to be explored in resistant cases, including Vitamin A toxicosis, as being presented in this case.

\section{Case presentation}

This is a case of a 44-year-old Caucasian male, end stage renal disease on Peritoneal Dialysis, who was admitted on Feb/10/2021 to Ruby Memorial Hospital, with an impending respiratory failure, past medical history of bed-bound cerebral palsy with gastric tube nutrition dependence and is non-verbal at baseline, chronic leukocytosis, chronic hypercalcemia, and end-stage renal disease on peritoneal dialysis for one year.

This patient presented to the hospital with acute hypoxic respiratory failure admitted to the medical intensive care unit, for sepsis secondary to multifocal pneumonia with a large left pleural effusion. Patient was COVID-19 negative, did not have any fevers or chills, but was tachycardic, tachypneic with respiratory rate in the $40 \mathrm{~s}$, low 02 saturation, even with high-flow nasal cannula, later, saturating appropriately on high BiPAP. Patient was later appropriately intubated, with chest tube placement for effusion drainage. He underwent multiple failed ventilator weaning attempts, which resulted in tracheostomy placement with nightly BiPAP. His hospital course was complicated due to worsening of his chronic

\author{
More Information \\ *Address for Correspondence: Anas Diab, \\ Department of Medicine, Section of Nephrology, \\ West Virginia University, Ruby Memorial Hospital \\ 4th Floor, HSCN Room 4076A, Morgantown, WV \\ 26506, USA, Email: anas.diab@hsc.wvu.edu \\ Submitted: May 26, 2021 \\ Approved: October 06, 2021 \\ Published: October 07, 2021 \\ How to cite this article: Diab A, Pellegrino B, \\ Neuman MM, Diab K. A case of resistant \\ hypercalcemia in a peritoneal dialysis patient \\ with underlying Vitamin A toxicosis. J Clini \\ Nephrol. 2021; 5: 081-083. \\ DOI: 10.29328/journal.jcn.1001079 \\ Copyright: (c) 2021 Diab A, et al. This is an \\ open access article distributed under the \\ Creative Commons Attribution License, which \\ permits unrestricted use, distribution, and \\ reproduction in any medium, provided the \\ original work is properly cited. \\ Check for updates \\ OPEN ACCESS
}

hypercalcemia, a right chest port hematoma, and peritoneal catheter-associated peritonitis. The patient completed a course of Vancomycin and Ceftazidime, with continued Nystatin fungal prophylaxis and Gentamycin cream at local PD site for concern of sepsis secondary to culture-negative peritoneal catheter-associated peritonitis.

Patient's work up for chronic hypercalcemia was negative for hyperparathyroidism, with no suspicion of malignancy, given his normal alkaline phosphatase, Sarcoidosis was not suspected due negative history and the absence of features on Chest Xray, 1,25-dihydroxyvitamin D and 25-hydroxyvitamin D levels, was within normal limits. A presumptive initial conclusion of hypercalcemia was thought to be due to chronic immobilization due to bed ridden.

Initially, the patient was treated in chronological order with the following:

- Feb 12/21: Intravenous Crystalloid with Plasmalyte at a $100 \mathrm{ml} / \mathrm{hr}$, with Intravenous Lasix IV $80 \mathrm{mg}$ started on for 5 days, to induce Calciuresis, since patient is still non-oliguric, had no effect on normalizing serum calcium.

- Feb 19/21: Calcitonin-salmon (MIACALCIN) 100 units/mL injection on for 3 days. With a temporarily normalizing calcium level.

- Feb 24/21: Cinacalcet $5 \mathrm{mg} / \mathrm{ml}$ oral suspension, (a 
Calcimimetic), as it has been suggested by Endocrinology even with naturally suppressed parathyroid hormone level, has no effect on his Serum calcium level (Figure 1).

- March/17/21: Pamidronate (AREDIA) $30 \mathrm{mg}$ in NS $500 \mathrm{~mL}$ IVPB, with serum calcium normalized temporarily, as it shown clearly from the table 1 .

- As for the PD fluid content, modified to use low calcium content of Dianeal PD fluid (calcium chloride of $18 \mathrm{mg} / 100 \mathrm{ml}$ ), with no significant change in serum calcium.

Reviewing his enteral feeding formula via his Gastric Tube, was founded to have a supplemental Vitamin A, so Free Retinol level was checked, and found to be toxic, and on Apr /26/21, Patient was immediately started on modified tube feeds per nutrition with low Vitamin A content, and follow up on his Calcium level, showed normalizing level in 2-3 weeks after implementing the new formula, as it shown in the following table:

Home Meds:

Ferrous sulfate (FERATAB) 324 mg every other day

Lamotrigine (LAMICTAL) tablet, $100 \mathrm{mg}$ daily

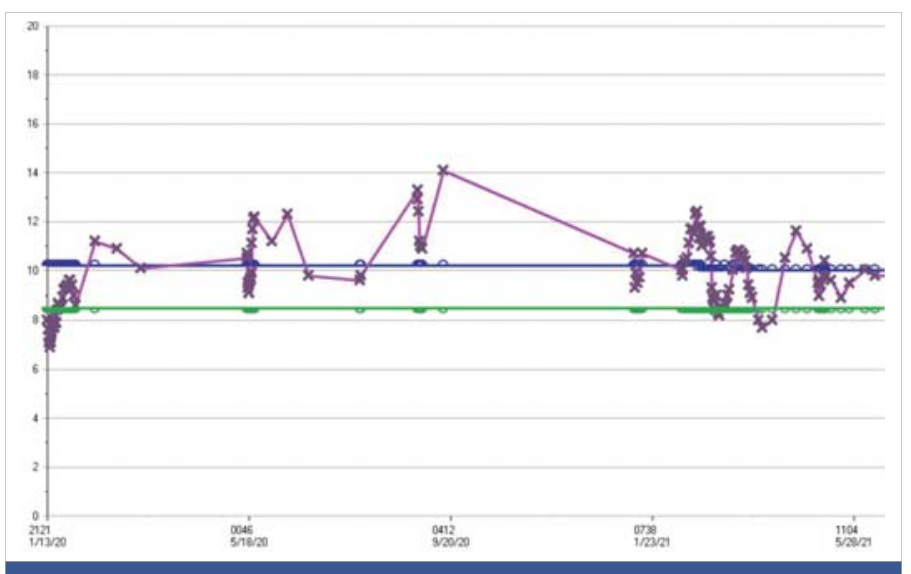

Figure 1: Serum level of Calcium in $\mathrm{mg} / \mathrm{dll}$, plotted against time.
Metoprolol tartrate (LOPRESSOR) $25 \mathrm{mg}$ twice daily

Pantoprazole (PROTONIX) 40 mg daily

Torsemide (DEMADEX) 20 mg daily

1.5\% dextrose Dianeal PD-2 (lactate based) peritoneal dialysis PREMIX solution - NO additives, $6 \mathrm{~L}$, Calcium Chloride $25.7 \mathrm{mg} / 100 \mathrm{ml}$.

\section{Discussion}

Vitamin A toxicity can be seen in acute and chronic forms. Acute toxicity leads to symptoms of nausea, vomiting, blurred vision, vertigo, and fatigue [2]. It usually occurs with ingesting more than 200,000 mcg of vitamin A. Chronic toxicity, usually seen in patients ingesting 20 times the recommended daily dose over a long period of time, such as 10,000 mcg daily, will start having neurological symptoms such as ataxia, visual impairments, but also muscle and bone pains, alopecia, dry skin, headaches, hepatotoxicity, hyperlipidemia, and very rarely hypercalcemia $[3,4]$. This patient was unable to verbalize symptoms but was often observed to be restless and grimacing, with very dry skin.

Vitamin A is a lipid soluble vitamin. It is stored in the liver and adipose tissue, therefore, it takes a significant amount of time to bring down levels, depending on body habitus and that is why circulating blood levels can be deceiving [5]. Toxicity is occasionally seen in adolescents treated for acne with excessive doses of retinoic acid, as well as chronic ingestion of certain foods such as chicken livers in certain populations.

It is unclear how chronic vitamin A toxicity can cause elevated level of calcium. Studies done on the matter allude to vitamin A possibly being involved in a pathway that can lead to elevated alkaline phosphatase increasing bone resorption and leading to osteoporosis [6]. Others have suggested it leads to increased bone remolding with greater stimulation of osteoclasts and osteolysis leading to increased brittle bone structures in animal models [7].

Table 1: Laboratory Values.

\begin{tabular}{|c|c|c|c|c|c|c|c|c|c|}
\hline Date & Intact PTH & Calcium & Albumin & Phosphorus & $\begin{array}{c}\text { Vitamin D 25, } \\
\text { Total }\end{array}$ & 1-25 Dihydroxyvitamin D & $\begin{array}{l}\text { Free Retinol } \\
\text { (VIT A) }\end{array}$ & SPEP & $\begin{array}{c}\text { Alkaline } \\
\text { Phosphatase }\end{array}$ \\
\hline Feb 19/21 & & 12.3 & & & & & & & \\
\hline Feb 20/21 & 41.2 & 11.8 & 2.4 & 4.4 & & 13 & & $\begin{array}{c}\text { No M-Spike was } \\
\text { observed }\end{array}$ & 94 \\
\hline Mar17/21 & & 10.8 & & & & & 130 & & \\
\hline Mar23/21 & & 10.1 & & & & & & & \\
\hline Mar30/21 & & & & & & & 152 & & \\
\hline Apr 07/21 & 236 & 8.0 & & & & & 173 & & \\
\hline Apr 26/21 & & 10.9 & & & & & 165 & & \\
\hline May06/21 & & 9.6 & & & 36 & & & & \\
\hline May11/21 & & 9.7 & & 10.6 & & & & & \\
\hline \multicolumn{10}{|c|}{$\begin{array}{l}\text { Retinol Binding Protein: } 19.7 \mathrm{mg} / \mathrm{dl} \text {, normal } 1.5-1.5 \mathrm{mg} / \mathrm{dl} \\
\text { Reference table: } \\
\text { Serum Calcium: } 8.5 \text { - } 10.0 \mathrm{mg} / \mathrm{dL} \text {; Serum Phosphorus: } 2.4-4.7 \mathrm{mg} / \mathrm{dL} ; \text { Albumin: } 3.5-5.0 \mathrm{~g} / \mathrm{dL} ; \text { Free Retinol (Vit A): } 32.5 \text { - } 78.0 \mathrm{mcg} / \mathrm{dL} ; \text { Vitamin D, } 25 \text { OH: } 30 \text { - } 100 \mathrm{ng} / \mathrm{mL} \text {; } \\
\text { 1-25 Dihydroxyvitamin D : } 18-64 \mathrm{pg} / \mathrm{ml} \text {; Intact PTH: } 8.5 \text { - } 77.0 \mathrm{pg} / \mathrm{mL} ; \text { Alkaline Phosphatase: } 45 \text { - } 115 \mathrm{U} / \mathrm{L}\end{array}$} \\
\hline
\end{tabular}


Focus for these patients should be on treating the underlying cause for hypercalcemia and attempts to bring down calcium levels if the patients are symptomatic. In this case the focus was to eliminate vitamin A intoxication through modifying tube feeds and emphasizing findings to family to avoid any unmeasured sources of vitamin A supplementation.

\section{Conclusion}

Hypercalcemia is a frustrating common complication in Dialysis population, in most cases an underlying cause or causes can be found, but in resistant cases, a rare condition needs to be explored including Vitamin A toxicosis, such in this case in a Cerebral Palsy patient on enteral feeding, which has a high content of Vitamin A, changing his enteral feeding formula, to a different formula with less Vitamin A, has resulted in resolving his Hypercalcemia.

\section{References}

1. Goodman WG, Goldin J, Kuizon BD, Yoon C, Gales B, et al. Coronaryartery calcification in young adults with end-stage renal disease who are undergoing dialysis. N Engl J Med 2000; 342:1478. PubMed: https://pubmed.ncbi.nIm.nih.gov/10816185/

2. Biesalski HK. Comparative assessment of the toxicology of vitamin $A$ and retinoids in man. Toxicology. 1989; 57: 117-161. PubMed: https://pubmed.ncbi.nlm.nih.gov/2665185/

3. Soprano DR, Soprano KJ. Retinoids as teratogens. Annu Rev Nutr. 1995; 15: 111-132.

PubMed: https://pubmed.ncbi.nlm.nih.gov/8527214/

4. Hathcock JN, Hattan DG, Jenkins MY, McDonald JT, Sundaresan PR, et al. Evaluation of vitamin A toxicity. Am J Clin Nutr. 1990; 52: 183-202. PubMed: https://pubmed.ncbi.nlm.nih.gov/2197848/

5. Cheruvattath R, Orrego M, Gautam M, Byrne T, Alam S, et al. Vitamin A toxicity: when one a day doesn't keep the doctor away. Liver Transpl. 2006; 12: 1888-1891.

PubMed: https://pubmed.ncbi.nlm.nih.gov/17133567/

6. Binkley N, Krueger D. Hypervitaminosis A and Bone. Nutr Rev. 2000; 58: 138-144.

PubMed: https://pubmed.ncbi.nlm.nih.gov/10860393/

7. Bélanger LF, Clark I. Alpharadiographic and histological observations on the skeletal effects of hypervitaminoses $A$ and $D$ in the rat. Anat Rec. 1967; 158: 443-451.

PubMed: https://pubmed.ncbi.nlm.nih.gov/4228328/ 